\title{
Selection of Transmission Network Development Plan Based on Adaptabil- ity Index
}

\author{
Chen Weihua*, Liu Lianguang and Chen Yanwei
}

\author{
Key Laboratory of Alternate Electrical Power System with Renewable Energy Sources, North China Electric Power \\ University, Beijing 102206, China
}

\begin{abstract}
In terms of the transmission network development case selection, there are deferent emphases for the development department, power dispatching and other departments, and evaluation indexes and methods in case selection of transmission network development are deferent to take, as a result it is difficult for the developing, scheduling and other departments of grid to form an objective, comprehensive, unified development scheme, and cause the contradiction among transmission network planning, construction, operation and other aspects. In order to solve the problems above, and make the grid planning, operation, construction and other departments evaluate the schemes of grid planning on the same platform, this paper presents a method to select an appropriate case of transmission network development planning based on adaptability and evidence theory. The concept of adaptability is established and characteristic path length, clustering coefficient, short-circuit current, maximum power flow of the line, net present value and other indicators are selected to quantitatively evaluate the degree of power grid development. Then the evidence theory is used to integrate the aspects of safety, economy and other adaptability indexes. The optional parameters are obtained to provide the basis for the selection of transmission network development planning. The method present in the paper solves the coordinate problem of transmission network development cases to select. Simulation of actual power grid development scheme selection shows the feasibility and validity of this method.
\end{abstract}

Keywords: Adaptability, case selection, evidence theory, plan, transmission network.

\section{INTRODUCTION}

With the development of national economy and the increasing of the electricity load, China's $500 \mathrm{kV}$ transmission network capacity has gradually become saturated. There are some problems such as some transmission lines overload and some short-circuit currents exceed the standard etc. Scheduling operation department and planning and development department often have different views and solutions on how to solve the above problem. This results double standards and cohesion difficulties in the transmission network construction, operation. How to reflect the characteristics of the $500 \mathrm{kV}$ grid objectively and to propose the network development planning to satisfy requirement for each department is currently one of the hot issues in the research [1,2]. Paper [3] proposed risk assessment method. Compared with the traditional method, it considers the occurrence probability and severity of events. Based on the theory of complex network, the evaluation method presented to research the development of power grid by literature [4], considering the topological structure of power grid. The literature $[5,6]$ adds security constraints in the economic optimization model. It can get the optimal solution with a certain range of security constraints. Literature [7-9] presents a multi-objective optimization model to get the optimal solution by satisfying the requirement of each target.
The above methods are the optimization methods in essence. It gets a satisfactory result to all sides by integrating all needs. However, the main cause of conflict in the same issue is that scheduling operation department and planning and development department have different views and ranges. So the optimization result cannot meet the request of the parties in the same optimal model with different boundary conditions. For a long time, the optimization scheme of network development is difficult to be approved unanimously by both scheduling operation department and planning and development department. It fully reflects the problem.

Considering the above problem, this paper is in the view of the whole cycle perspective of the power grid development. It focuses on different stages of the power grid development. It fully uses the mature grid index system to complete each other. It can improve the fitness of power grid development plan to meet the development requirements of all aspects of power grid. Therefore, this paper presents the concept of adaptability for grid development scheme and applies evidence theory to realize the safety and economy of fitness to all aspects. And it can provide decision support for the development of power grid.

\section{CONCEPT AND CONSTRUCTION OF ADAPT- ABILITY}

\subsection{Concept of Adaptability}

In traditional grid evaluation indexes, certain result is obtained generally by the comparison between calculation re- 
sults with the threshold. With the continuous development of the grid, this type of index has many disadvantages. First, it can not reflect the obvious degree of grid feature. When the index difference between calculation value and threshold is large, the evaluation result is reliable. When the index calculation value is close to the threshold, the evaluation results may be wrong for the error of calculation. Secondly, the evaluation index is independent of each other. İt cannot provide effective information to other indicators. Finally, the traditional index is not conducive to the integration of various indicators in the development of the power grid comprehensive judgment. Adding different evaluation index of the several aspects together simply is not an effective method. And the results are often unable to be recognised by all aspects [10].

Based on the above reasons, this paper presents the concept of adaptability. Define the adaptability varies in $[0,+$ infinity). It is used to describe adaptability between a grid development plan and external factors in the specified criterion reference. The greater A adaptability of the plan is, the more plan can meet the request of the parties, the more plan should be preferred.

\subsection{Construction Adaptability}

Modern power system belongs to complex networks, its structure feature is the basis for the safe and stable operation of power grid. At present, the characteristic path length and clustering coefficient of power grid topology can be selected as base for adaptability degree construction. Due to the small world topology is of adervantage, so the characteristic path length and clustering coefficient of the structure are used as construction adaptability functions.

$A_{T k}=\left|\left(L_{k}-L_{S k}\right) / L_{S k}\right|$

where, $A_{T k}$ is the construction adaptability of the characteristic path length. $L_{k}$ and $L_{S k}$ are the characteristic path lengthes.

Similarly, the adaptability of the clustering coefficient are as following.

$A_{J k}=\left|\left(C_{k}-C_{S k}\right) / C_{S k}\right|$

where, $A_{J k}$ is the construction adaptability of the clustering coefficient. $C_{k}$ and $C_{S k}$ are the clustering coefficientes.

\subsection{Running Adaptability}

Combined with $500 \mathrm{kV}$ transmission grid status and development trend, the short circuit current and the line maximum power flow can be selected base for running adaptability [11]. The short circuit current reflects the link degree of power grid. The bigger the short-circuit current is, the closer the grid structure is. But he bigger the short-circuit current is, the closer the grid structure is, the high the risk of breaker interrupting capacity is. Therefore, the short circuit current value should not be too small or too large. With the circuit breaker capacity constraints, the short circuit current must be limited in the range of breaker interrupting capacity.

$$
A_{D k}=\left\{\begin{array}{cc}
D_{m} / 2-\left|D_{m} / 2-\sum_{i=1}^{n_{1}} D_{i} / n_{1}\right| & , \quad \forall D_{i}<D_{m} \\
0 & , \forall D_{i} \geq D_{m}
\end{array}\right.
$$

where, $A_{D k}$ is running adaptability of short circuit current, $A_{D k} \geq 0 . D_{m}$ is the largest breaker interrupting capacity. $D_{i}$ is the short circuit current of transformer substation. $n_{1}$ is substation number.

In the formula, the more satisfied with short circuit current by the aspects, the bigger the adaptability is. The less satisfied with short circuit current by the aspects, the smaller the adaptability is. In particular, if the short circuit current exceeds the maximum breaker interrupting capacity, then the adaptability degree is 0 , the plan can not be used.

In the short circuit current of $500 \mathrm{kV}$ substation area power grid, short circuit current may be very small in a vast majority of substation, while short circuit current may be larger in some individual substations. This will get small average short circuit current overall. By formula (3), it will get a large degree of running adaptability of short circuit current. This is not consistent with the actual situation, so formula (3) needs to be modified as following.

$$
A_{D k}=\left\{\begin{array}{cc}
\alpha_{k} \times\left(D_{m} / 2-\left|D_{m} / 2-\sum_{i=1}^{n_{1}} D_{i} / n_{1}\right|\right) & , \quad \forall D_{i}<D_{m} \\
0 & , \quad \forall D_{i} \geq D_{m}
\end{array}\right.
$$

where, $\alpha_{k}$ is the correction coefficient, and

$\alpha_{k}=\left\{\begin{array}{cc}1, & D_{S}<0.4 \\ 0.6 & , \quad D_{S} \geq 0.4\end{array}\right.$

Line maximum power flow reflects power grid load. The smaller the line maximum power flow is, the smaller power grid load is. The bigger the line maximum power flow is, the bigger power grid load is. The running adaptability of line maximum power flow is not good if Line maximum power flow is too small or too bigger [12]. With the maximum transmission capability limit, Line maximum power flow reflects power grid load. The line maximum power flow must be restricted to the range of maximum transmission capability.

$A_{P k}=\left\{\begin{array}{cc}P_{m} / 2-\left|P_{m} / 2-\sum_{j=1}^{n_{2}} P_{j} / n_{2}\right|, & \forall P_{j}<P_{m} \\ 0 \quad & \forall P_{j} \geq P_{m}\end{array}\right.$

where, $A_{P k}$ is the running adaptability of line maximum power flow, $A_{P k} \geq 0 . P_{m}$ is the maximum transmission capability. $P_{j}$ is the line maximum power flow. And $n_{2}$ is a line number.

In the formula, the more satisfied with line maximum power flow, the bigger the adaptability is. The less satisfied with line maximum power flow by the aspects, the smaller the adaptability is. In particular, if the line maximum power 
flow exceeds the maximum transmission capability, then the plan can not be used.

\subsection{Economic Adaptability}

With the development of economy and the reform of market, the network economy is getting more and more attention. At present, economy and is almost equally important position with safety. Economic indicators are more and more widely applied in electric power system. The main aspect is investment [13].

In this paper, economic adaptability is constructed based on the net present value to emphasize the time value of project. It is from the view of the project life-cycle perspective.

$$
A_{N k}=A_{\max }-\frac{\sum_{t=0}^{n_{3}}\left(C_{I}-C_{O}\right)_{t} \times(1+b)^{-t}}{\sum_{t=0}^{n_{3}} I_{t}(1+b)^{-t}}
$$

Where, $A_{N k}$ is economical adaptability. $A_{\max }$ is investment quota. $C_{I}$ is capital input, and $C_{O}$ is capital output. $t=0,1, \cdots, n_{3}$ is the project cycle year. $b$ is the benchmark rate of return. $I_{t}$ is the final years of investment.

Economic adaptability reflects the use efficiency of funds in the plan. The bigger the limited investment plan obtains the contribution, the bigger economical adaptability is. The smaller the limited investment plan obtains the contribution, the smaller economical adaptability is.

\section{EVIDENCE THEORY AND APPLICATION}

In recent years, evidence theory has been applied widely in electric power system $[14,15]$. The three elements of evidence theory is establishing recognition framework, constructing distribution function, evidence combination decision.

\subsection{Establishing Recognition Framework}

Recognition framework is the set of all decision problems, its role is to deciding target of evidence theory. Each element is mutually exclusive recognition and independence of each the inside the frame. When an element is choosed, it means giving up other elements.

In the selection of transmission network development planning, the ultimate goal is to choose a case that can satisfy each requirement and coordinate development from the whole cycle of development planning. Therefore, all the transmission network development plannings establishes the recognition framework. There are $\mathrm{N}$ schemes in the research scope, then the recognition is as following.

$\Psi \in\left\{F_{1}, F_{2} \cdots, F_{N}\right\}$

\subsection{Constructing Distribution Function}

In the evidence theory, the main role of distribution function is allocating decision supporting among all the elements in the recognition framework to highlight the characteristics of each frame element. The definition of the distribution function in the evidence theory is as following.

Recognition framework is $\Psi$, the distribution allocation meets

$$
\left\{\begin{array}{c}
2^{\Psi} \rightarrow[0,1] \\
w(\phi)=0 \\
\sum_{A \subseteq \Psi} w(A)=1 \\
w(\Psi)=1-\sum_{A \subset \Psi} w(A)
\end{array}\right.
$$

In the formula, when $A \subset \Psi, A \neq \phi$, the $m(A)$ reflects selecting degree of frame elements A. $m(\Psi)$ reflects that uncertain selecting is assigned to the whole recognition framework.

In the selection of transmission network development planning, the role of the distribution function is assigning security, economic and other aspects adaptability to the elements in recognition framework. It can be represented by an optional index. The higher the optional index is, the stronger the plan comprehensive adaptability on safety and economy is, the more meet the requirements of the planning, operation and other departments. The planning should be choosed. This paper puts the optional degree distribution function as following.

$w=w_{r} \times c_{a}$

where, $w_{r}$ is the relatively optional degree distribution function. $c_{a}$ is the optional global coefficient.

The adaptability function of a transmission network development plan $\mathrm{k}$ is $A_{* k}$, where $A_{* k} \in\left\{A_{T k}, A_{J k}, A_{D k}, A_{P k}, A_{N k}\right\}$. The method of probability distribution is generally used for the plans comparing. Each plan index and ratio of all index are used as following.

$R_{k}=A_{*_{k}} / \sum_{k=0}^{N} A_{*_{k}}$

The formula is the probability distribution of the adaptability. This method is simple and convenient. But the small disturbance degree plan may interferent plan selection. In practical application, the adaptation plan of a small degree is not used generally. And it cannot provide support for the other plan selection. To other plans, the adaptation plan of a small degree cannot increase or decrease the optional degree of other plans. To recognition framework, the adaptation plan of a small degree is actually illustrating the optional degree of the frame. Based on the above reasons, the traditional probability distribution function is reconstructed. When the value of adaptability function is less than 0.2 , and the ranking of the plan in all the plans is less than the 3 bits, the adaptability function of the plan is set to 0 , as following.

$w_{r}\left(R_{k}\right)=\left\{\begin{array}{cc}A_{*_{k}} / \sum_{k=0}^{N} A_{*_{k}} & \text { else } \\ 0 & R_{k}<0.2 \text { and }_{k}<3\end{array}\right.$ 


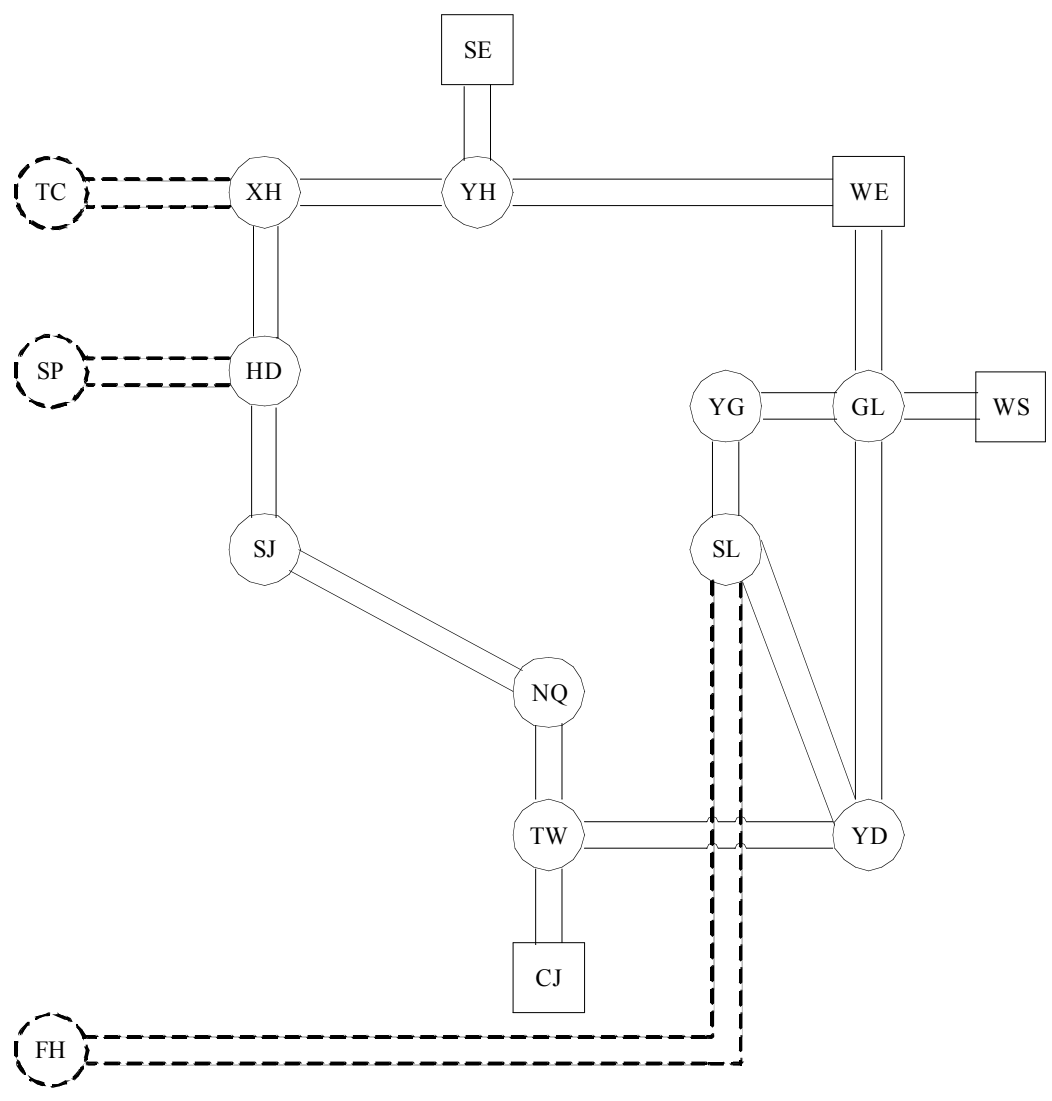

Fig. (1). Power network diagram of initial year.

where, $O_{k}$ is the sort ascending function.

Generally, the greater the adaptability of the plan is, the more it is adapt to the request of the parties, and the larger optional degree should be assigned. The smaller the adaptability of the plan is, the less it is adapt to the request of the parties, and the smaller optional degree should be assigned. Based on the above considerations, the global coefficient is used to highlight these differences as following.

$w_{a}=\left\{\begin{array}{cc}\max \left(F_{*_{k}}\right) / c & \max \left(F_{*_{k}}\right) \leq c \\ 1 & \text { else }\end{array}\right.$

where, $\mathrm{c}$ is constant as the inflection point of distribution function to treat different adaptability plan separately.

Integrated formulas from (11) to (13), the optional degree of distribution function expression is obtained as following.

$$
w(A)=\left\{\begin{array}{cc}
w_{r}(A) \times w_{a} & A=\left\{F_{k}\right\} \\
1-\sum_{k=0}^{N} m\left(\left\{F_{k}\right\}\right) & A=\Psi
\end{array}\right.
$$

\subsection{Evidence Combination Decision}

The optional distribution functions of characteristic path length adaptability, clustering coefficient adaptability, short circuit current adaptability, line maximum power flow adaptability, net present value rate adaptability are $w_{1}, w_{2}$, $w_{3}, w_{4}, w_{5}$ respectively. The recognition framework is
$\Psi \in\left\{F_{1}, F_{2}, \cdots, F_{N}\right\}$. The optional distribution value matrix is as following.

$$
\left\{\begin{array}{l}
w_{1}\left(F_{1}\right), w_{1}\left(F_{2}\right), \cdots, w_{1}\left(F_{N}\right), w_{1}(Y) \\
w_{2}\left(F_{1}\right), w_{2}\left(F_{2}\right), \cdots, w_{2}\left(F_{N}\right), w_{2}(Y) \\
w_{3}\left(F_{1}\right), w_{3}\left(F_{2}\right), \cdots, w_{3}\left(F_{N}\right), w_{3}(Y) \\
w_{4}\left(F_{1}\right), w_{4}\left(F_{2}\right), \cdots, w_{4}\left(F_{N}\right), w_{4}(Y) \\
w_{5}\left(F_{1}\right), w_{5}\left(F_{2}\right), \cdots, w_{5}\left(F_{N}\right), w_{5}(Y)
\end{array}\right\}
$$

In the evidence theory, the orthogonal rule is generally used for the combination of number to obtain the comprehensive optional degree value of each power grid development plan. Then the most feasible plan of power grid development can be obtained by the comparison of the overall optional degree value. The rule is shown as following.

$w \in\left(\left(w_{1} \oplus w_{2}\right) \oplus \cdots \oplus w_{k}\right)$

\section{CASE STUDY}

This paper takes a $500 \mathrm{kV}$ power system in a province as an examples to verify the feasibility of the proposed algorithm. The research time range is from 2010 to 2015 . The $500 \mathrm{kV}$ power network diagram in the grid starting years is shown as following. In the Fig. (1), circles and squares represent substations and power plants respectively. And the dotted lines represent connected parts to the surrounding province grids. 
Table 1. Results of cases.

\begin{tabular}{|c|c|c|c|c|c|}
\hline & \multicolumn{5}{|c|}{ Calculated Value } \\
\hline & Path Length & $\begin{array}{c}\text { Clustering } \\
\text { Coefficient }\end{array}$ & $\begin{array}{c}\text { Short Circuit } \\
\text { Current (kA) }\end{array}$ & $\begin{array}{c}\text { Biggest Power Flow } \\
\text { (MW) }\end{array}$ & $\begin{array}{c}\text { Amount of } \\
\text { Investment (G\$) }\end{array}$ \\
\hline \hline Case1 & 4.4026 & 0.4936 & 46.7 & 1697 & 1827 \\
\hline Case2 & 4.401 & 0.4931 & 54.8 & 2437 & - \\
\hline Case3 & 4.4311 & 0.4937 & 46.5 & 3.1 \\
\hline Case4 & - & - & 65 & 3300 & - \\
\hline Case5 & - & - & - & 1743 & - \\
\hline Case6 & 4.4053 & 0.4938 & 41.2 & 4.5 \\
\hline
\end{tabular}

Table 2. Adaptability indexes of cases.

\begin{tabular}{|l|c|c|c|c|c|}
\hline & \multicolumn{5}{|c|}{ Adaptability } \\
\hline & Path Length (\%) & $\begin{array}{c}\text { Clustering } \\
\text { Coefficient (\%) }\end{array}$ & $\begin{array}{c}\text { Short Circuit } \\
\text { Current (kA) }\end{array}$ & $\begin{array}{c}\text { Biggest Power Flow } \\
\text { (MW) }\end{array}$ & $\begin{array}{c}\text { Amount of Invest- } \\
\text { ment (G\$) }\end{array}$ \\
\hline \hline Case1 & $0.29 \%$ & $0.26 \%$ & 16.3 & 1503 & 1373 \\
\hline Case2 & $0.33 \%$ & $0.36 \%$ & 8.2 & 763 & 4.1 \\
\hline Case3 & $0.36 \%$ & $0.24 \%$ & 16.5 & - & - \\
\hline Case4 & - & - & 0 & 0 & - \\
\hline Case5 & - & - & - & 1457 & 5.4 \\
\hline Case6 & $0.23 \%$ & $0.22 \%$ & 21.8 & \\
\hline
\end{tabular}

Table 3. Optional indexes of cases.

\begin{tabular}{|c|c|c|c|c|c|c|}
\hline & \multicolumn{6}{|c|}{ Optional } \\
\hline & Path Length & $\begin{array}{c}\text { Clustering } \\
\text { Coefficient }\end{array}$ & $\begin{array}{c}\text { Short Circuit } \\
\text { Current (kA) }\end{array}$ & $\begin{array}{c}\text { Biggest Power } \\
\text { Flow (MW) }\end{array}$ & $\begin{array}{c}\text { Amount of } \\
\text { Investment (G\$) }\end{array}$ & \begin{tabular}{c} 
Whole Scheme \\
\hline Case1
\end{tabular} \\
\hline \hline Case2 & 0.261 & 0.251 & 0.271 & 0.353 & 0.203 & 0.319 \\
\hline Case3 & 0.225 & 0.202 & 0.043 & 0.227 & 0.156 & 0.326 \\
\hline Case4 & - & 0.271 & 0.289 & 0.092 & - & 0.093 \\
\hline Case5 & - & - & - & - & - & 0 \\
\hline Case6 & 0.298 & 0.276 & 0.397 & 0.328 & 0.315 & 0.503 \\
\hline
\end{tabular}

\subsection{Index Calculation}

There are 6 power grid development plans.

Case1, buliding substation LT and XY, line SJ-LT and LT-TW, power plant CM, stoping line HD-XH, connecting line SJ-NQ.

Case2, buliding substation LT and XY, line SJ-LT and LT-TW, power plant CM, stoping line HD-XH, GL-YD, YH-WE, and SJ-NQ.

Case3, buliding substation XY, stoping HD-XH, power plant CM, connecting line SJ-NQ.
Case4, buliding substation LT and XY, line HD-YG, SJLT, LT-TW, and TW-YD, power plant CM.

Case5, buliding substation XY, line TW-YD, power plant $\mathrm{CM}$, stoping line YH-WE.

Case6, buliding substation LT and XY, line SJ-LT, HDXH LT-TW, TW-YD, power plant CM, installing series reactor in line HD-SJ and YH-WE, stoping line HD-XH.

The calculation results of each plan are shown as following Table 1.

Based on adaptability calculation method, the adaptability of each grid development plan is shown as following Table 2 . 
The optional degree of each grid development plan is obtained by using evidence theory, as shown in the following table. It can be seen from the table, through the optional distribution, optional degree of case6 increases relatively, and optional degree of other cases are decreases relatively. So case6 has obvious advantages. This provides powerful support for selection of transmission network development plan Table 3.

\subsection{Result Analysis}

Analysis of the plans shows, Case4 focuses on strengthening the grid which results the short circuit current exceeding limit. So Case4 is not feasibility. Case 5 focuses on decreasing the short circuit current. This case does not strengthen the grid effectively to result the risk of line maximum power flow. So Case5 is also not feasibility. In Case2, the phenomenon of buliding and stoping repeated which reflects the poor coordination between the planning department and operation department. Case 2 is ineffective but with large investment. Case3 solves the short circuit current and line maximum power flow problems to some degree, but the case is poor adaptability to load development. Case 1 and Case6 are good power grid development plans. Compared with Case1, Case6 is better at the arrangement of the project timing and improving the safety of power grid operation. In summary, Case6 is the best plan.

\section{CONCLUSION}

1) This paper reveals that different focuses on power grid development between the development department and dispatching department is one of the main reasons causing the disconnection of power grid development planning, construction, operation and other aspects. This paper presents the concept of adaptability. Through the adaptability of grid characteristic length, clustering coefficient, short circuit current, line maximum power flow, investment, the adaptability between power grid development and realistic state, as well as the external environment, is analyzed from the power grid structure, operation, economic and other aspects. It can provide the basis for the assessment of power grid development.

2) This paper provides the system frame and basic method to solve the contradiction of power grid planning. With the evaluation index is further enriched, it will be able to gradually solve the realistic problems in power system planning, and promote the healthy development of power grid.

\section{CONFLICT OF INTEREST}

The authors confirm that this article content has no conflict of interest.

\section{ACKNOWLEDGEMENTS}

Declared none.

\section{REFERENCES}

[1] L. Zhang, T. Ye, and Y. Xin, "Problems and measures of power grid accommodating large scale wind power," Proceedings of the CSEE, vol. 30, pp. 1-9, 2010.

[2] X. Liang, P. Zhang, and C. Yong, "Recent advances in high-voltage direct-current power transmission and its developing potential," Power System Technology, vol. 36, pp. 1-9, 2012.

[3] B. Wang, D. You, and X. Yin, "A security risk assessment system of complicated power grid based on multiple factor analysis," Power System Technology, vol. 35, pp. 40-45, 2011.

[4] S. Xiao, and J. Zhang, "Assessment of power grid vulnerability based on small-world topological model," Power System Technology, vol. 34, pp. 64-68, 2010.

[5] Z. Chen, K. Xie, and J. Zhang, "Optimal model and algorithm for day-ahead generation scheduling of transmission grid security constrained convention dispatch," Automation of Electric Power Systems, vol. 33, pp. 10-14, 2009.

[6] B. Yang, W. Yang, and X. Qing, "A full-scenario SCED with coordinative optimization of hydro-thermal-wind power," Proceedings of the CSEE, vol. 33, pp. 2-9, 2013.

[7] L. Chen, X. Gu, and W. Li, "Multi-objective optimization and dicision-making of extended black-start schemes considering restoration security margin," Automation of Electric Power Systems, vol. 38, pp. 39-46, 2014.

[8] Y. Jing, H. Bai, and J. Zhang, "Multi-objective optimization design and operation strategy analysis of a solar combined cooling heating and power system," Proceedings of the CSEE, vol. 32, pp82-88, 2012.

[9] D. Chen, Q. Gong, and Q. Hui, "Multi-objective generation dispatching for wind power integrated system adopting improved biogeography-based optimization algorithm," Proceedings of the CSEE, vol. 32, pp. 150-159, 2012.

[10] L. Liu, W. Zhao, and Z. Wang, "Research on economic evaluation contents and indices for large power grid construction," Electric Power Construction, vol. 34, pp. 22-26, 2013.

[11] X. Xiong, X. Qi, and O. Jinxin, "Effect of doubly-fed wind turbines short-circuit current on second harmonic escapement of transformer protection," Proceedings of the CSEE, vol. 34, pp. 2201-2209, 2014.

[12] Q. Wang, F. Jiang, and R. Ma, "Power flow analysis of power grid connected with wind farms based on state transition," Power System Technology, vol. 37, pp. 1880-1886, 2013.

[13] Z. Tan, E. Wu, and L. Ju, "A model for contrastive analysis on risk of income from investment in different wind power resource regions," Power System Technology, vol. 37, pp. 713-719, 2013.

[14] Y. Yan, F. C. Lee, and P. Mattavelli, "Comparison of small signal characteristics in current mode control schemes forpoint-of-load buck converter applications," IEEE Transactions on Power Electronics, vol. 28, pp. 3405-3414, 2013.

[15] X. Li, J. Zhang, and Y. Zhang, "Short-term load forecasting for similar days based on support vector machine and dempster-shafer theory," Power System Technology, vol. 34, pp. 143-147, 2010.

\begin{tabular}{lcc}
\hline Received: June 10, 2015 & Revised: July 29, 2015 & Accepted: August 15, 2015 \\
C) Weihua et al.; Licensee Bentham Open. &
\end{tabular}

This is an open access article licensed under the terms of the (https://creativecommons.org/licenses/by/4.0/legalcode), which permits unrestricted, noncommercial use, distribution and reproduction in any medium, provided the work is properly cited. 